\title{
Biocompatibility of 13-93 Bioactive Glass-SiC Fabric Composites
}

\author{
Jewon Park ${ }^{* * * *}$, Hyein Na ${ }^{* * * *}$, Sung-Churl Choi $* *$, and Hyeong-Jun Kim ${ }^{* * ;}$ \\ *Engineering Ceramics Center, Korea Institute of Ceramic Engineering and Technology, Icheon 17303, Korea \\ **Division of Materials Science and Engineering Hanyang University, Seoul 04763, Korea
}

(Received March 7, 2019; Revised March 18, 2019; Accpted March 19, 2019)

\begin{abstract}
Bioactive glass (BG) finds limited use as a bone replacement material owing to its low mechanical properties. In order to solve this problem, the micro-sized 13-93 BG was prepared as a fabric composite with SiC microfibers, and its mechanical properties and biocompatibility were investigated in this study. The tensile strengths of BG-SiC fiber-bundle composites increased in proportion to the number of $\mathrm{SiC}$ fibers. In particular, even when only one $\mathrm{SiC}$ fiber was substituted, the tensile strength increased by $81 \%$ to $1428 \mathrm{MPa}$. In the early stage of the in-vitro test, a silica-rich layer was formed on the surface of the 13-93 BG fibers. With time, calcium phosphate grew on the silica-rich layer and the BG fibers were delaminated. On the other hand, no products were observed on the $\mathrm{SiC}$ fibers for 7 days, therefore, $\mathrm{SiC}$ fibers are expected to maintain their strength even after transplantation in the body.
\end{abstract}

Key words : Bioactive glass, Bioglass-SiC fabric composite, Mechanical properties, Biocompatibility, Biomedical applications

\section{Introduction}

$\mathrm{T}$ here is increasing interest in ceramic materials for human body insertion treatment related to aging and health. Further, the importance of organic-inorganic composites and porous bioceramic materials is increasing, considering the need for biocompatibility between materials and the living tissues in the human body.

Porous bioceramics promote biological reactions, however, they cannot maintain the mechanical properties. This issue is hard to overcome physically as there exists a technical contradiction between the simple physical properties. In order to simultaneously realize high porosity, biocompatibility, and mechanical properties, it is necessary to graft materials and design them at the same time. It is expected that the above problem can be solved if a fabric can be made of bioactive glass (BG) fiber and a high toughness bio-inert fiber material.

BG was first developed by Hench of England in the early 1970s and commercialized owing to its excellent biocompatibility. The advantages of BG are it is tissue-friendly and does not induce the formation of fibrous tissue around it. In addition, $\mathrm{CaO}$ and $\mathrm{P}_{2} \mathrm{O}_{5}$ are present in $\mathrm{BG}$, so that the surface is efficiently dissolved and hydroxyapatite (HAP) can be easily formed. ${ }^{1)}$ BG is applied to coating materials, 3D scaffolds, dental materials, and charging materials for pro-

${ }^{\dagger}$ Corresponding author: Hyeong-Jun Kim

E-mail : goldbud@kicet.re.kr

Tel : +82-31-645-1459 Fax : +82-31-645-1492

ORCID

http://orcid.org/0000-0001-8681-9014 moting bone formation, like HAP. ${ }^{2)}$ However, BG has limited applicability owing to its low mechanical properties, despite its biocompatibility. In this context, various composite materials in the forms of coatings, fillers, and whiskers have been considered to solve this problem. However, these materials could not address the contradiction of high porosity and high strength. ${ }^{2,3)}$

Therefore, we fiberized $\mathrm{BG}$ and fabricated it in a porous and flexible form. In addition, it was expected that the mechanical properties would be enhanced by combining a biologically inert fiber material and the BG fiber. Silicon carbide ( $\mathrm{SiC}$ ) was selected as the material to be used as a fabric composite with BG. The chemical inertness of $\mathrm{SiC}$ suggests high resistance to corrosion in harsh environments such as body fluids. In addition, its high modulus of elasticity and low coefficient of friction render $\mathrm{SiC}$ an ideal material for smart implants and biosensors in vivo., ${ }^{4,5)}$

In this study, the BG-SiC fabric composite was prepared and the changes in the mechanical properties according to the proportion of $\mathrm{SiC}$ fibers were observed. The biocompatibility of the BG-SiC fabric composites was investigated by identifying the crystalline phase present on the surface after reacting with a simulated body fluid (SBF).

\section{Experimental Procedure}

\subsection{Fabrication of $B G$ fibers and $B G-S i C$ fabric composite \\ In this study, the 13-93 BG composition (53 $\mathrm{SiO}_{2}, 4 \mathrm{P}_{2} \mathrm{O}_{5}$, $20 \mathrm{CaO}, 5 \mathrm{MgO}, 6 \mathrm{Na}_{2} \mathrm{O}, 12 \mathrm{~K}_{2} \mathrm{O}$, all in wt\%) was selected. Its glass transition temperature $\left(\mathrm{T}_{\mathrm{g}}\right)$, dilatometric softening temperature $\left(\mathrm{T}_{\mathrm{dsp}}\right)$, and half sphere temperature $\left(\mathrm{T}_{1 / 2}\right)$ are}




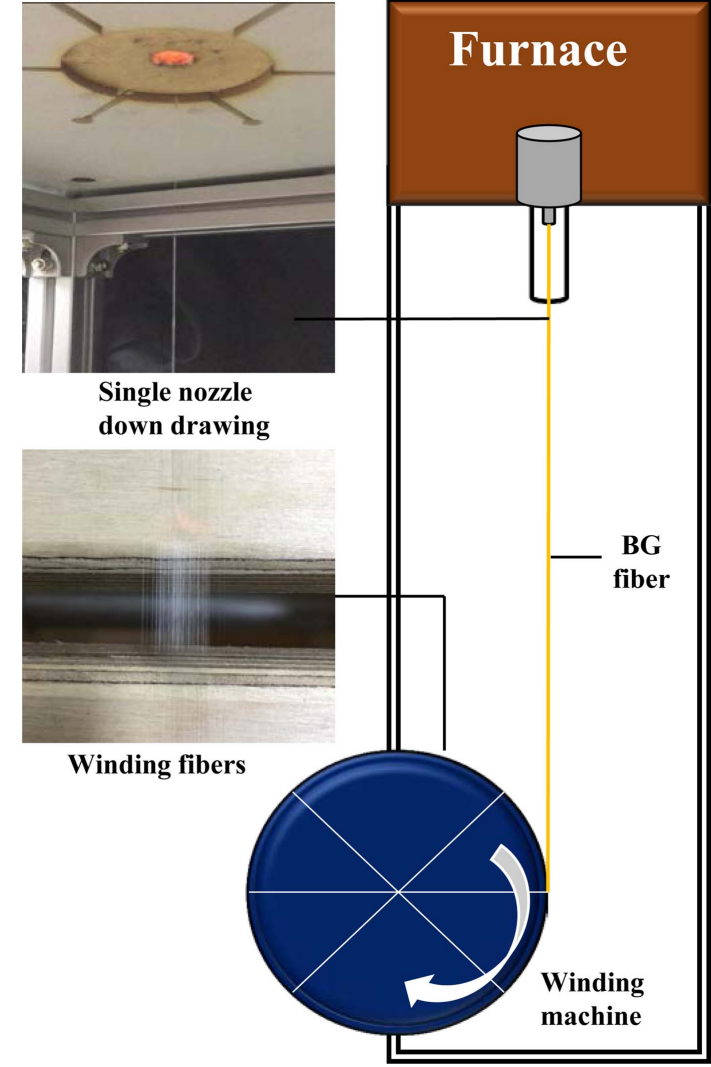

Fig. 1. Melt spinning system for the fabrication of 13-93 BG fibers. The distance between the nozzle and the winding machine is $1.3 \mathrm{~m}$. The diameter of the drum is $44 \mathrm{~cm}$ and the motor is attached.

$598.14^{\circ} \mathrm{C}, 641.3^{\circ} \mathrm{C}$, and $1154^{\circ} \mathrm{C}$, respectively. Fig. 1 is a schematic of a melt-spinning system.

This cullet was placed in a $\mathrm{Pt}-10 \% \mathrm{Rh}$ crucible equipped with a single nozzle with a diameter of $2 \mathrm{~mm}$, and the glass was fiberized at $1295^{\circ} \mathrm{C}$. The fiberizing temperature was experimentally determined by trial and error. Winding was performed by varying the winding force and the number of rotations within the ranges 47.6-430 $\mathrm{N}$ and 50-150 rpm, respectively. The 13-93 BG fiber length produced under each condition was over $20 \mathrm{~m}$. The fiber diameter was measured for each condition. A fabric composite of dimensions $30 \times 30 \mathrm{~mm}$ was fabricated from the BG fiber and amorphous SiC fiber.

\subsection{Measurement of the tensile strengths of $B G$} fibers and BG-SiC fiber composite

The tensile strength was measured to evaluate the mechanical properties of 13-93 BG single fiber and 13-93 BG-SiC fiber-bundle composites. The test was carried out in accordance with ASTM standard D3379. A universal material testing machine (INSTRON 5544, INSTRON, USA) was used. The measurement conditions were a load cell capacity of $10 \mathrm{KN}$, a cross-head speed of $0.5 \mathrm{~mm} / \mathrm{min}$, and a gage length of $20 \mathrm{~mm}$. The 13-93 BG-SiC fiber composite was a bundle that consisted of $10 \mathrm{BG}$ and $\mathrm{SiC}$ fibers in total. The
Table 1. Ionic Concentration (mM) in SBF and Human Plasma

\begin{tabular}{ccc}
\hline & \multicolumn{2}{c}{ Ion concentration (mM) } \\
\cline { 2 - 3 } & Blood Plasma & $\begin{array}{c}\text { Simulated Body Fluid } \\
\text { (SBF) }\end{array}$ \\
\hline $\mathrm{Na}^{+}$ & 142.0 & 142.0 \\
$\mathrm{~K}^{+}$ & 5.0 & 5.0 \\
$\mathrm{Mg}^{2+}$ & 1.5 & 1.5 \\
$\mathrm{Ca}^{2+}$ & 2.5 & 2.5 \\
$\mathrm{Cl}^{-}$ & 103.0 & 147.8 \\
$\mathrm{HCO}_{3}{ }^{-}$ & 27.0 & 4.2 \\
$\mathrm{HPO}_{4}{ }^{2-}$ & 1.0 & 1.0 \\
$\mathrm{SO}_{4}{ }^{2-}$ & 0.5 & 0.5 \\
\hline
\end{tabular}

tensile strength was measured by controlling the number ratio of each fiber. The diameters of the two fibers were kept constant in the range $16-20 \mu \mathrm{m}$.

\subsection{In-vitro testing of $\mathrm{BG}-\mathrm{SiC}$ fabric composite}

For the evaluation of the bioactivity of the 13-93 BG and SiC fibers, an in vitro test was conducted by using a SBF

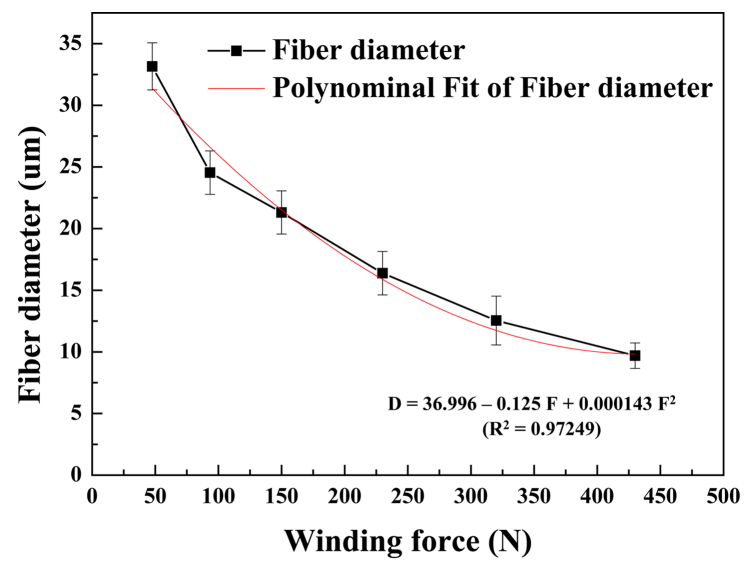

(a)

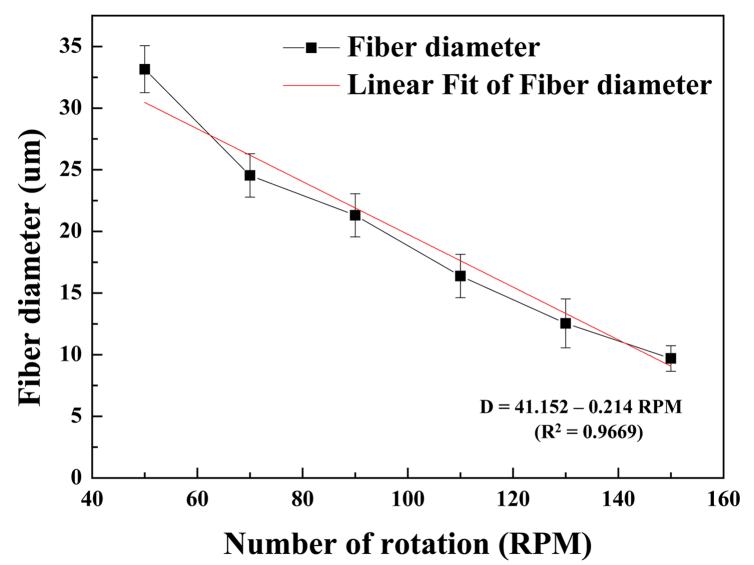

(b)

Fig. 2. Change in the diameter of 13-93 BG fiber (represented by $\mathrm{x}$ ) when wound with continuous fibers. (a) Fiber diameter-winding force and (b) fiber diameternumber of rotations. 


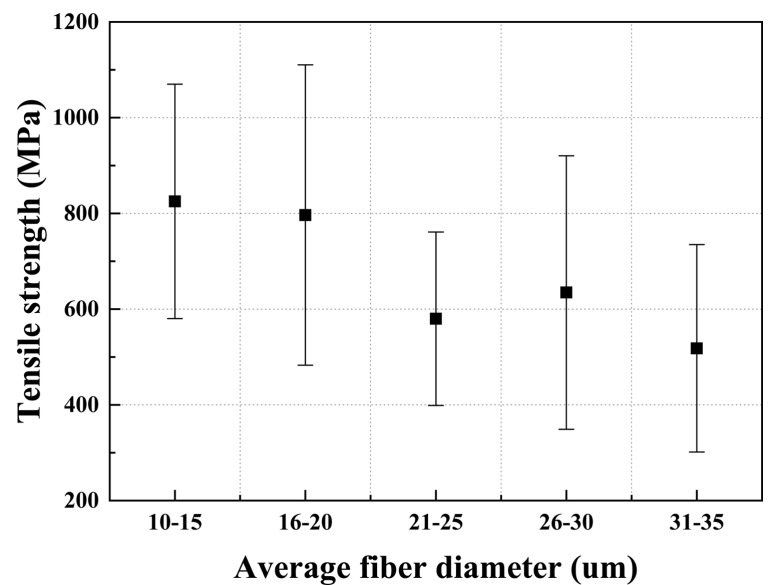

Fig. 3. Tensile strength as a function of the change in the average diameter of 13-93 BG fiber.

solution. Table 1 shows the ionic concentrations of the SBF solution and human blood plasma. The test was performed in the static state by using a thermo-hygrostat maintained

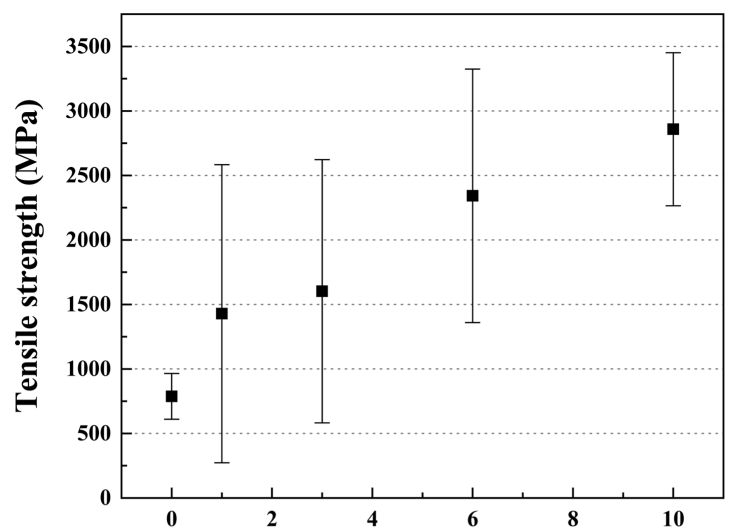

The number of SiC fibers in BG-SiC fiber composite (a)

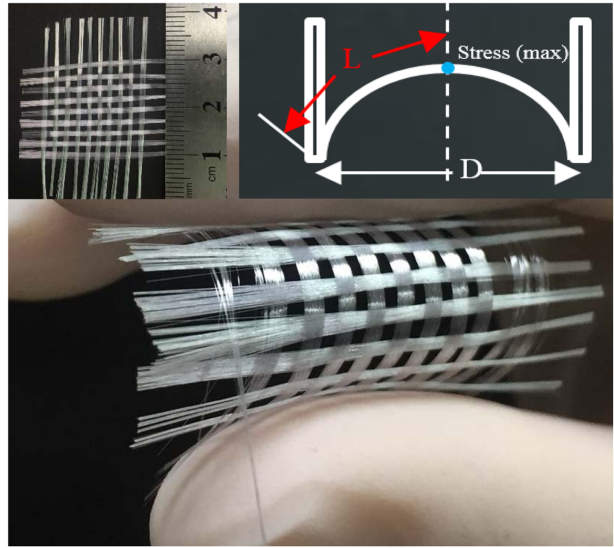

(b)

Fig. 4. Mechanical properties of 13-93 BG-SiC fabric composite. (a) Tensile strength-number of $\mathrm{SiC}$ fibers (each fiber composite is a bundle of 10 fibers in total) and (b) two-point bending with hand after weaving with 13-93 BG-SiC fabric composite. at a temperature of $36.5 \pm 1^{\circ} \mathrm{C}$. The reaction was carried out for seven days. After the in-vitro test, the BG, $\mathrm{SiC}$ fiber, and SBF reaction solution were filtered through a polytetrafluoroethylene filter. The remaining residue was dried in a desiccator for one day.

\subsection{Analysis of the microstructure and crystalline phases}

The microstructure and composition of the 13-93 BG and $\mathrm{SiC}$ fibers that reacted with the SBF solution were confirmed by scanning electron microscopy (SEM; JSM-6390, JEOL, Japan) and energy dispersive spectrometry (EDS; AZtecOne, Oxford Instruments, UK). X-ray diffraction (XRD; D/MAX-2500/PC, Rigaku, Japan) analysis was also performed to confirm the substances produced. The measurement conditions were an acceleration voltage of $40 \mathrm{kV}$, a scan speed of $5 \% \mathrm{~min}$, and $2 \theta$ range $10^{\circ}$ to $80^{\circ}$.

\section{Results and Discussion}

The change in the diameter of the 13-93 BG fiber according to the winding force and number of rotations is shown in Fig. 2. It was assumed that the amount of melt glass discharged through the nozzle would remain constant. As expected, the average glass fiber diameter decreased with increasing winding force and number of rotations. The fiber diameter is related to the winding force and number of rotations, and is expressed by the following regression equations:

$$
\begin{aligned}
& \mathrm{D}=36.996-0.125 \mathrm{~F}+0.000143 \mathrm{~F}^{2}\left(\mathrm{R}^{2}(\mathrm{adj})=0.97249\right) \\
& \mathrm{D}=41.152-0.214 \mathrm{RPM}\left(\mathrm{R}^{2}(\mathrm{adj})=0.9669\right)
\end{aligned}
$$

where $\mathrm{D}$ is the fiber diameter, $\mathrm{F}$ is the winding force, and $\mathrm{RPM}$ is the number of rotations.

The large $R^{2}$ (adj) for the two equations suggest their reliabilities are very high. The required diameter of the BG

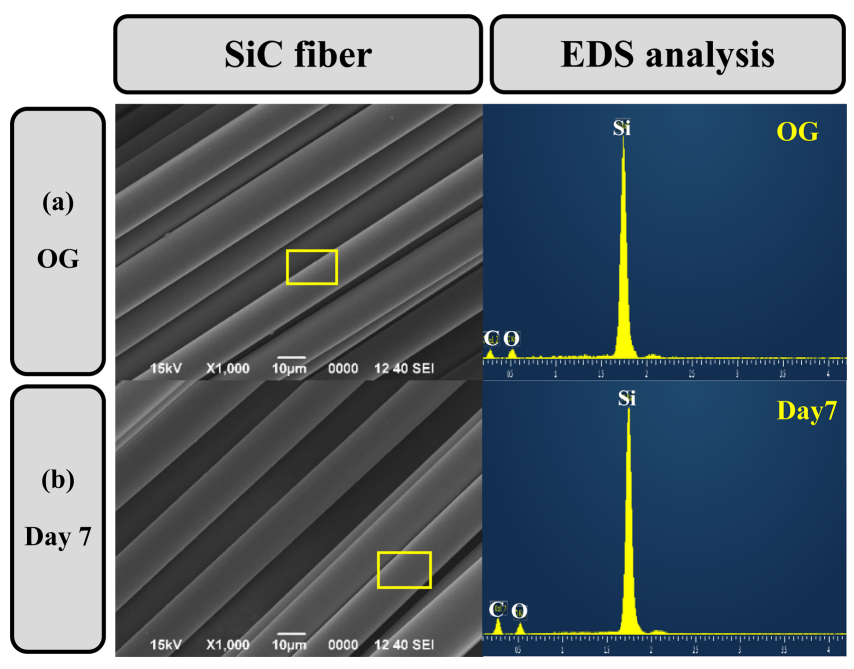

Fig. 5. Scanning electron microscopy and energy dispersive spectrometry analysis of $\mathrm{SiC}$ fiber with in-vitro test in SBF solution for 7 days. 
fiber can be obtained by adjusting the winding force and number of rotations.

In an attempt to continuously draw fibers, the glass viscosity was measured at $1295^{\circ} \mathrm{C}$, which had been experimentally determined through trial and error. In general, the viscosity of glass tends to decrease when its temperature exceeds $\mathrm{T}_{\mathrm{g}}$. The viscosity dependence of the glass temperature at high temperatures follows Arrhenius behavior, but the activation energy for viscous flow is not constant. Therefore, the viscosity of the glass was calculated by using the Vogel-Fulcher-Tamman (VFT) equation (eq. 3). ${ }^{6)}$

$$
\log \mathrm{\eta}=\mathrm{A}+\mathrm{B} /\left(T-T_{0}\right)
$$

Here, $\mathrm{A}, \mathrm{B}$, and $\mathrm{T}_{0}$ are constants. These three constants can be calculated by using the reference points $\left(\mathrm{T}_{\mathrm{g}}, \mathrm{T}_{\mathrm{dsp}}, \mathrm{T}_{1 / 2}\right)$ in the VFT equation, and the results are as follows.

$$
\log \eta=1.79+1192.15 /(T-481.29)
$$

The viscosity value corresponding to the temperature of $1295^{\circ} \mathrm{C}$ was $\eta=10^{4.25} \mathrm{dPa} \mathrm{s}$. This is higher than $10^{2.5}-10^{3.5}$ $\mathrm{dPa} \mathrm{s}$, which is known as the ideal viscosity range for continuous fiber drawing. On the other hand, in Vedel's VFT curve $^{7}$ for $13-93 \mathrm{BG}, 1295^{\circ} \mathrm{C}$ corresponds to a viscosity lower than $10^{2} \mathrm{dPa}$ s. It is considered that a separate study on the difference in the viscosity values is needed.

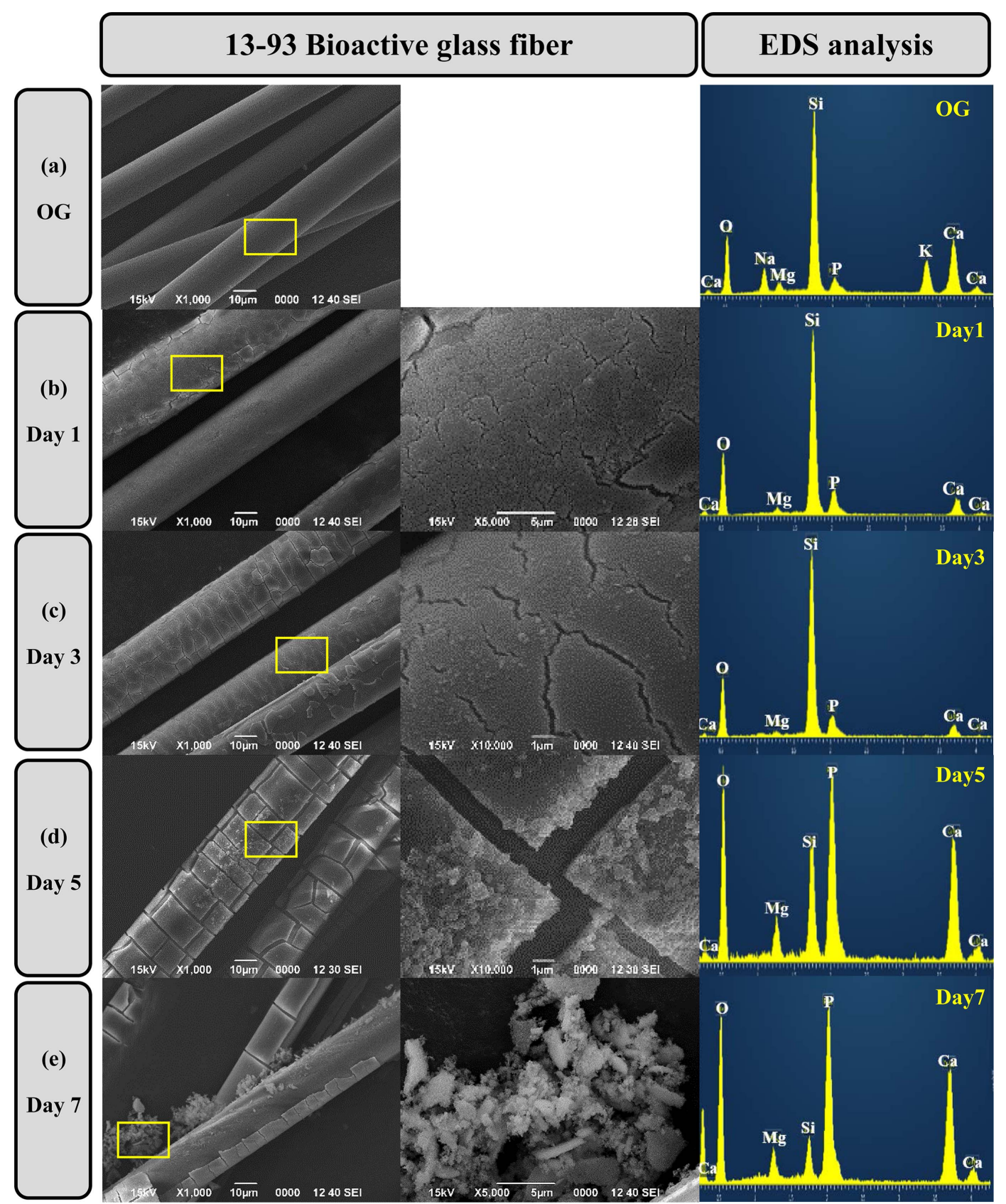

Fig. 6. Scanning electron microscopy and energy dispersive spectrometry analysis of 13-93 BG fiber with in-vitro test in SBF solution for 7 days. 
Figure 3(a) shows that the tensile strength increased with decreasing glass fiber diameter. The tensile strength was the highest at $852 \mathrm{MPa}$ when the average fiber diameter was $10-15 \mu \mathrm{m}$. The increased strength is considered to be due to the lowered probability of BG surface defects. ${ }^{8)}$ Fig. 3 (b) suggests that the 13-93 BG and $\mathrm{SiC}$ fibers were woven at an interval of $2 \mathrm{~mm}$ and that the fabric was very flexible. According to Hooke's Law ( $\delta \propto P L / A E)$, when an elastic body is subjected to an external force beyond its elastic limit, its deformation becomes larger with decreasing crosssectional area. ${ }^{9)}$ Therefore, the BG prepared as fibers can be processed into highly flexible fabrics.

The results of the measurement of the tensile strength of the BG-SiC fiber-bundle composite are displayed in Fig. 4. The number of SiC fibers affected the tensile strength. In particular, when one SiC fiber was substituted, the tensile strength was $1428 \mathrm{MPa}$, which was $81 \%$ higher than that of a bundle consisting of BG fibers alone. The strength of the fiber-bundle composite with $6 \mathrm{SiC}$ fibers increased rapidly to $2342 \mathrm{MPa}$. The tensile strength of single fibers and bundles were measured to be $796 \mathrm{MPa}$ and $787 \mathrm{MPa}$, respectively, for BG and $2833 \mathrm{MPa}$ and $2858 \mathrm{MPa}$, respectively, for $\mathrm{SiC}$. Since $1 \mathrm{~Pa}=1 \mathrm{~N} / \mathrm{m}^{2}$, the mechanical properties of each fiber do not change as the area increases from a single fiber to a bundle, whereas forces are acting simultaneously. Therefore, the BG-SiC fiber-bundle composite material is effective in improving the strength, since stress dispersion occurs in the $\mathrm{SiC}$ fiber.

Figure 5 and 6 show the surface changes after in-vitro testing of the BG-SiC fabric composite with a SBF solution for seven days. Fig. 5 shows the reaction of the SBF solution with the $\mathrm{SiC}$ fiber. The surface of the $\mathrm{SiC}$ fibers that reacted for seven days was kept clean. This represents the inherent bio-reactivity of the bio-inert $\mathrm{SiC}$ fibers. ${ }^{10)}$ According to the in-vitro test of the BG-SiC fabric composite, it is expected that the $\mathrm{SiC}$ fiber will play a role in maintaining the strength of the BG-SiC fabric composite.

Figure 6 displays the reaction of the SBF solution with the 13-93 BG fibers. In the case of the 13-93 BG fiber reacting with the solution for one day, a layer with a high content of silica was formed on the surface and cracks occurred. This is because the reaction with the solution elutes the network modifier to form a $\mathrm{SiO}_{2}$-rich layer that shrinks due to the residual stress. ${ }^{11)}$ After 3 days, small particles are visible as reaction products on the surface. There was no significant difference in the components of the BG fibers reacted for 1 day and 3 days. This is because the SBF solution component is already present within the 13-93 $\mathrm{BG}$, and the reactivity is slow due to the high $\mathrm{SiO}_{2}$ content. ${ }^{12)}$ After 5 days of $\mathrm{BG}$ fiber reaction, a full-scale change occurred. The alkaline earth ions that had been eluted with the solution began to deposit again on the surface. The particles grew into reactive substances containing high concentrations of $\mathrm{Ca}$ and P. After 7 days, the particles became coarser and the Si concentration was very low compared to those of $\mathrm{Ca}$ and $\mathrm{P}$. In addition, the delamination of the silica-rich layer further increased com- pared to that observed at the beginning of the reaction. This can be attributed to an increase in the reaction time between the BG fiber and the SBF solution. BG is transplanted into the human body, and various ions such as $\mathrm{Ca}^{2+}$, $\mathrm{P}^{5+}$, and $\mathrm{Na}^{+}$are released from its surface. Network modifiers, such as $\mathrm{Na}^{+}$and $\mathrm{Ca}^{2+}$, form weak bonds with nonbridging oxygens, and hence, their leaching rates are very high. ${ }^{13-15)}$ Some studies have shown that the negative surface potential of the hydroxyl groups present on the surface of the BG fibers attracts the $\mathrm{Ca}^{2+}$ existing in the solution, resulting in the formation of an amorphous Ca-related oxide and generation of a positive surface potential. ${ }^{16-18)}$ It is known that phosphorus ions are attracted to form amorphous calcium phosphate (ACP) on the $\mathrm{SiO}_{2}$ layer of the glass surface. Then, the ACP is crystallized and grown as a hydroxycarbonate apatite (HCP) crystal. $^{15)}$

The 13-93 BG fiber and SiC fiber were reacted in the SBF solution for 7 days, and the results of crystalline phase anal-

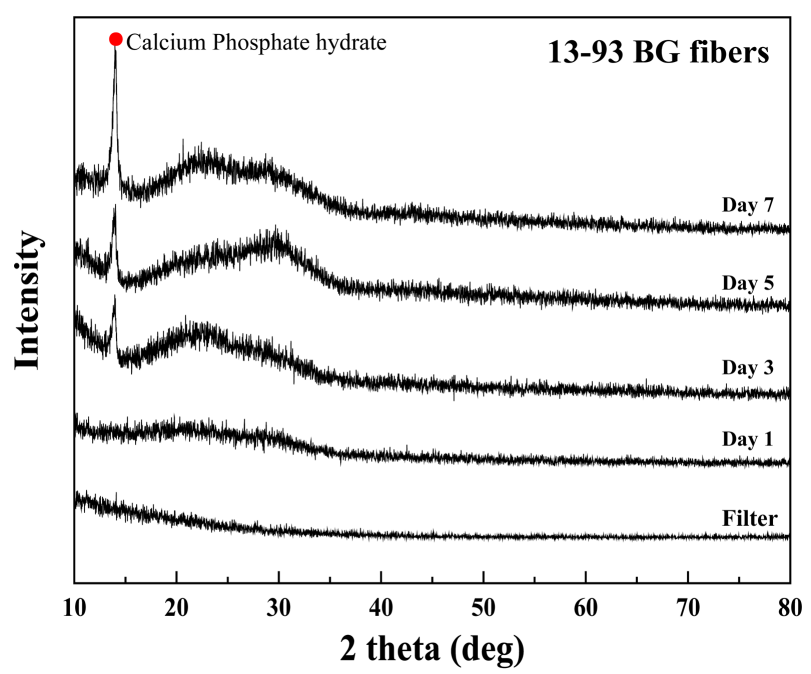

(a)

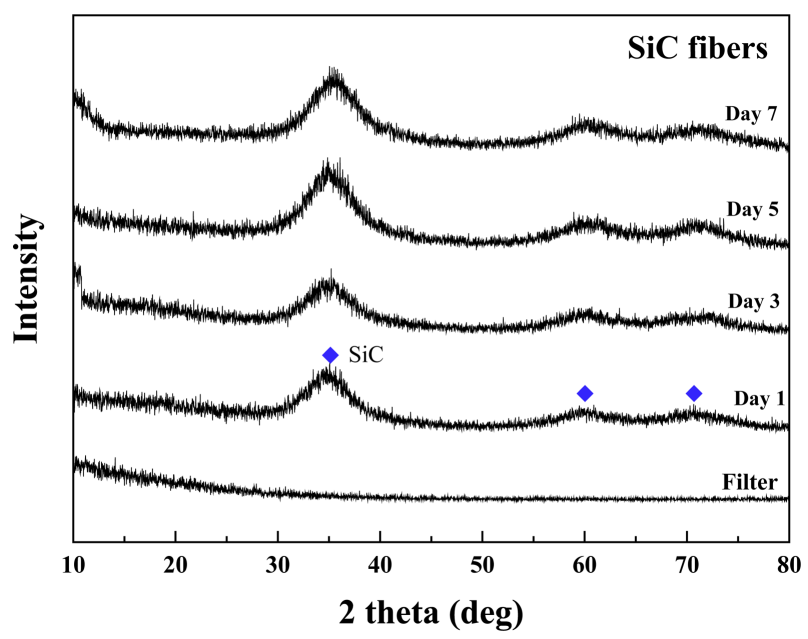

(b)

Fig. 7. X-ray diffraction analysis of (a) 13-93 BG fiber and (b) SiC fiber with in vitro test in SBF solution for 7 days. 
ysis of the reactants are shown in Fig. 7. In the case of 13-93 BG fibers, 3 days after the reaction, a crystalline phase peak was observed at $2 \theta=14^{\circ}$ and a hollow peak at $2 \theta=20^{\circ}$ to $30^{\circ}$. The particles formed on the BG fiber surface were the crystalline phase of calcium phosphate hydrate. After 5 days, many calcium phosphate hydrate crystals were formed on the surface and the peak intensity increased. Unlike the mechanism proposed by Hench, the calcium phosphate crystalline phase was produced, and not ACP or HCP. On the other hand, no product formed on the $\mathrm{SiC}$ fiber. Therefore, when the BG-SiC fabric composite is transplanted into the body, it is expected that the $\mathrm{SiC}$ fiber remains in the transplantation site and maintains the strength, even though BG is dissolved due to the biological reaction.

\section{Conclusions}

In the present study, BG-SiC fabric composites were prepared and changes in the mechanical properties were confirmed. In addition, an in-vitro test was carried out with SBF solution and the biocompatibility analyzed.

The 13-93 BG-SiC fiber-bundle composites showed an increase in strength that was in proportion to the number of $\mathrm{SiC}$ fibers replaced in the bundle, and the tensile strength was $81 \%$ higher than that of BG fiber-bundles, even when only one $\mathrm{SiC}$ fiber was substituted. The 13-93 BG-SiC fabric composite, which is highly flexible beyond its elastic limit, is expected to provide toughness. As a result of the in-vitro test, a silica-rich layer was formed on the 13-93 BG fiber surface. Damage to the fiber surface was inevitable due to the reaction with the solution. Furthermore, over time, calcium phosphate began to form on the silica-rich layer of the BG fiber, while the SiC fiber maintained the initial state. When the BG-SiC fabric composite is transplanted into the human body, its strength will be maintained owing to the bio-inert nature of the SiC fibers.

\section{REFERENCES}

1. L. L. Hench, An Introduction to Bioceramics; Ed. by J. Wilson, World scientific, London, 1993.

2. H. J. Kim, "Status of Bioactive Glass," Ceramist, 21 [3] 216-32 (2018).

3. L. L. Hench, "Chronology of Bioactive Glass Development and Clinical Applications," New J. Glass Ceram., 3 [2] 67 73 (2013).

4. M. Levinshtein, and S. Rumyantsev, "Silicon Carbide (SiC)," pp. 93-147 in Properties of Advanced Semiconductor Materials: GaN, AIN, InN, BN, SiC, SiGe, Ed. by M. Shur, M. Levinshtein, S. Rumyantsev, John Wiley and Sons, New York, 2001.
5. X. Li, X. Wang, R. Bondokov, J. Morris, Y. H. An, and T. S. Sudarshan, "Micro/Nanoscale Mechanical and Tribological Characterization of $\mathrm{SiC}$ for Orthopedic Applications," J. Biomed. Mater. Res. B Appl. Biomater., 72 [2] 353-61 (2004).

6. M. Ahmed and D. A. Earl, "Characterizing Glaze-Melting Behavior via HSM," Am. Ceram. Soc. Bull., 81 [3] 47-51 (2002).

7. E. Vedel, H. Arstila, H. O. Ylänen, L. Hupa, and M. Hupa, "Predicting Physical and Chemical Properties of Bioactive Glasses from Chemical Composition. Part 1: Viscosity Characteristics," Glass Technol.: Eur. J. Glass Sci. Technol., Part A, 49 [6] 251-59 (2008).

8. E. Pirhonen, L. Moimas, and M. Brink, "Mechanical Properties of Bioactive Glass 9-93 Fibres," Acta Biomater., 2 [1] 103-7 (2006).

9. Suresh T. Gulati, Jamie Westbrook, Stephen Carley, Hemanth Vepakomma, and Toshihiko Ono, "45.2: Two Point Bending of Thin Glass Substrate," SID Int. Symp. Dig. Tech. Pap., 42 [1] 652-54 (2012).

10. A. Oliveros, A. Guiseppi-Elie, and S. E. Saddow, "Silicon Carbide: A Versatile Material for Biosensor Applications," Biomed. Microdevices, 15 [2] 353-68 (2013).

11. D. E. Clark, C. G. Pantano Jr., and L. L. Hench, Corrosion of Glass; pp. 21-31, Books for Industry and The Glass Industry, New York, 1979.

12. C. Y. Kim, A. E. Clark, and L. L. Hench, "Compositional Dependence of Calcium Phosphate Layer Formation in Fluoride Bio Glasses,” J. Biomed. Mater. Res., 26 [9] 1147-61 (1992).

13. Y. S. Kim and C. Y. Kim, "Physical Properties and Hydroxyapatite Formation of Low Alkali Containing Bioglass,” J. Korean Ceram. Soc., 31 [12] 1521-28 (1994).

14. C. Y. Kim, A. E. Clark, and L. L. Hench, "Early Stage of Calcium Phosphate Layer Formation in Bioglass," J. NonCryst. Soilds, 113 [2-3] 195-202 (1989).

15. J. H. Lee, J. W. Lee, C. Y. Kim, "Apatite Formation Behavior on Bioactive Glasses with Glass Composition and Reaction Solution," J. Korean Ceram. Soc., 37 [11] 1105-13 (2000).

16. H.-M. Kim, T. Himeno, M. Kawashita, J.-H. Lee, T. Kokubo, and T. Nakamura, "Surface Potential Change in Bioactive Titanium Metal during the Process of Apatite Formation in Simulated Body Fluid," J. Biomed. Mater. Res, A, 67 1305-9 (2003).

17. H.-M. Kim, T. Himeno, T. Kokubo, and T. Nakamura, "Process and Kinetics of Bone like Apatite Formation on Sintered Hydroxyapatite in a Simulated Body Fluid," Biomaterials, 26 [21] 4366-76 (2005).

18. T. Kokubo, "Design of Bioactive Bone Substitutes Based on Biomineralization Process," Mater. Sci. Eng. C, 25 [2] 97-104 (2005). 